\title{
A study on serum vitamin B12 levels in type 2 diabetic women and its correlation with metformin therapy
}

\author{
Yashaswini L. S. ${ }^{1 *}$ \\ DOI: https://doi.org/10.17511/ijmrr.2019.i04.12 \\ 1* Yashaswini L. S., Associate Professor, Department of General Medicine, Sree Rajarajeswari Medical College and Hospital, Bangalore, \\ Karnataka, India.
}

Background: Diabetes Mellitus (DM) is a major emerging health issue and the risk factors are varied in women making them susceptible to it. Metformin is most preferred and widely used drug worldwide due to various reasons. Vitamin B12 deficiency in DM caused by Metformin is least known side effect. Objective: This study was taken up to assess the correlation between deficiency and duration and dose of metformin treatment. Methods: This being a hospital based observational study, 650 Diabetic women were evaluated by detailed questionnaire, general physical examination, fasting blood glucose (FBS), post prandial blood glucose (PPBS), serum Vitamin B12 levels, CBC and NCS. Results: The mean age of the cases was $51.98 \pm 5.17$ years. $164 / 408$ cases (on metformin therapy for $>3$ months) had low vitamin B12 as against 22/242 controls (never on metformin therapy). Mean Serum vitamin B12 was low in cases with less duration of DM when compared to cases with longer duration. Vitamin B12 deficiency was correlated with anemia and neuropathy. Conclusions: Metformin treatment in cases is associated with higher prevalence of Vitamin B12 deficiency which increases with duration of DM and dose of metformin. Deficiency correlated with development of macrocytic anemia and worsening of neuropathy. In some, symptoms of deficiency are difficult to diagnose and can be irreversible if left untreated (like neuropathy). Routine screening of Vitamin B12 levels, CBC, NCS should be done in all diabetic women at the beginning of metformin therapy, and yearly thereafter. Treatment and prevention of deficiency is easy, cheap, safe, and effective.

Keywords: Diabetes Mellitus, Metformin, Vitamin B12, Anemia, Neuropathy

Corresponding Author

Yashaswini L. S., Associate Professor, Department of General Medicine, Sree Rajarajeswari Medical College and Hospital, Bangalore, Karnataka, India. Email: yashaswini1486@yahoo.co.in
How to Cite this Article

To Browse
Yashaswini L S. A study on serum vitamin B12 levels in type 2 diabetic women and its correlation with metformin therapy. Int J Med Res Rev. 2019;7(4):332-338.

Available From

https://ijmrr.medresearch.in/index.php/ijmrr/article/ view/1077

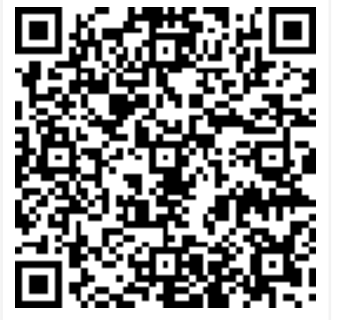

Manuscript Received 2019-06-04

Conflict of Interest No

Review Round 1
2019-06-14
Funding
Nil

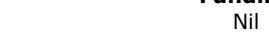

(c) 2019 by Yashaswini L. S. and Published by Siddharth Health Research and Social Welfare Society. This is an Open Access article licensed under a Creative Commons Attribution 4.0 International License https://creativecommons.org/licenses/by/4.0/ unported [CC BY 4.0].

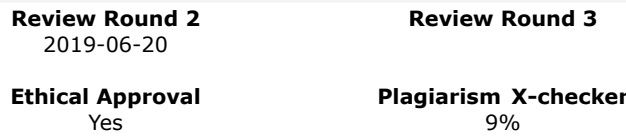




\section{Introduction}

Type 2 Diabetes Mellitus (NIDDM) being the most common endocrine disease, is the major cause of morbidity and mortality affecting millions of people worldwide. The prevalence of diabetes is higher in men than women, but there are more women suffering from complications of DM than men. Research has shown that many risk factors like obesity, lack of physical activity, family commitments and pressures are more common among women than men in all population subgroups.

Circumstances such as retirement from employment, separation, divorce, and widowhood may make middle-aged women vulnerable to low family incomes and inadequate health care coverage so that they may forego needed services, including preventive care for diabetes [1]. Metformin is most widely used antidiabetic drug worldwide. It is indeed the first line drug in DM due to various reasons like cost effectiveness, beneficial effect on weight, high potency, least side effects, long standing evidence of safety. Approximately, 120 million diabetic patients are treated with this drug worldwide.

Most patients tolerate metformin well, with most common side effects relating to GIT (nausea vomiting, diarrhea, lactic acidosis), which are usually mild and resolve with time [2]. Vitamin b12 deficiency in DM induced by metformin therapy is least known side effect and is more likely with prolonged use of drug, higher doses taken and in elderly [3]. Vitamin B12 is water soluble vitamin required for hematopoiesis, functioning of central and peripheral nervous system and in DNA synthesis of all cells. The reported Vitamin B12 deficiency in the general population of India varies from $12 \%$ to $67 \%[4,5]$ as against that in western countries $(5-7 \%)$.

A predominantly vegetarian diet could be one of the causes of higher prevalence of Vitamin B12 deficiency in India [4]. Deficiency of Vitamin B12 causes megaloblastic anemia, neuropathy, memory and cognitive impairment. Neuropathy also being a common complication in DM has similar clinical features to Vitamin B12 deficient neuropathy (indistinguishable by nerve conduction studies also). Vitamin B12 deficient neuropathy can be misdiagnosed as diabetic neuropathy or it may contribute in worsening of diabetic neuropathy [3].
Metformin-induced Vitamin B12 deficiency has been ascribed to the binding of the hydrophobic tail of biguanide to the hydrocarbon core of membranes. The biguanide group being positively charged (protonated) gives a positive charge to the membrane and can displace divalent cations such as calcium [6]. The uptakes of Vitamin B12 into the ileal cells are calcium dependent and can thus be impaired by metformin [7]. Indian diets have also been reported to be low in calcium. This could be another factor causing higher prevalence of Vitamin B12 deficiency [8].

Vitamin B12 deficiency results in

01. Hematological manifestations like megaloblastic anemia, pancytopenia, hyper segmented neutrophils, suppression of immune system [9].

02. Neurological symptoms like tingling, numbness, muscle weakness, balance problems, psychiatric symptoms (depression, psychosis) [9].

03. Decrease in both Vitamin B12 and folate concen-trations might result in megaloblastic anemia, such as to an increase of serum total homocysteine concentration, an independent risk factor for cardiovascular disease [9].

From the reports in the medical literature, diminished absorption of vitaminB12 manifested as decreased serum Vitamin B12 levels, occurred as early as 3-4 months after the use of metformin. Symptomatic deficiency of Vitamin B12 according to most reports occurred 5-10 years after the use of metformin. This is in line with the established knowledge that the body store of Vitamin B12 is huge $(2500 \mu \mathrm{g})$ in comparison to daily loss/requirement $(1-2 \mu \mathrm{g})$, and depletion of the pre-existing body store Vitamin B12 thus takes 3-15 years [9]. Biochemical deficiency is considered when serum vitamin b12 levels are between $200 \mathrm{pg} / \mathrm{ml}$ $300 \mathrm{pg} / \mathrm{ml}$ and symptoms of deficiency occur when levels go below $200 \mathrm{pg} / \mathrm{ml}$. Vitamin B12 supplements often reverse hematological manifestations within days to weeks. Reversal of neurological damage is doubtful [9].

The first case of Vitamin B12 deficiency-induced megaloblastic anemia due to long-term (8 years) metformin treatment was reported in 1980 [9]. In Indian scenario, few studies are conducted regarding an association between metformin treatment in DM and low serum vitamin B12 levels. The impact of metformin use on an already Vitamin B12 deficient Indian population is an interesting question. 
Hence this study was taken up to assess the correlation between serum Vitamin B12 level and duration and dose of metformin treatment. The findings of the study will probably help in better management of DM in future.

\section{Objectives of Study}

-To estimate serum Vitamin B12 levels in Diabetic women

-To correlate serum Vitamin B12 levels with dose and duration of metformin treatment

-To assess clinical features in Vitamin B12 deficient Diabetic cases

\section{Materials and Methods}

Setting: The study was conducted on female Diabetic patients attending OPD or admitted in the inpatient Medicine department of SreeRajarajeswari Medical College, Bangalore

Duration of study: 1st of January 2015 to 31 st of January 2018.

Type of study: Hospital based observational crosssectional study

Sampling method: Random sampling was done among the patients attending OPD and admitted in wards. The study population consisted of 650 diabetic (type 2) women. All the women in the diabetic group were newly confirmed diabetics as per ADA criteria or were already receiving treatment for DM.

Inclusion criteria: Female patients with type 2 diabetes mellitus aged between $30-70$ years. A detailed history was taken regarding duration of diabetes, dose and duration of metformin therapy, co-morbid conditions, and symptoms of peripheral neuropathy (tingling sensation, pricking sensation, and paresthesia). Patients were also examined for body weight and height.

Exclusion criteria: Diabetes in pregnancy, chronic alcohol abuse, chronic renal failure, malabsorption, chronic diarrhea, critical illness, pernicious anemia, gastrointestinal surgery, Crohns disease, autoimmune thyroid disease, chronic hepatitis, and the use of oral/ parenteral Vitamin B12 or multivitamin supplements.

Data collection procedure: The following tests were done on patients-FBS (fasting blood glucose), PPBS (post prandial blood glucose), Hba1c, serum
Creatinine, hemoglobin, mean corpuscular volume, nerve conduction studies. Vitamin B12 levels were estimated by electrochemiluminescence. The hospital records, patient's prescriptions, and medicines were searched for prescription of any Vitamin B12-containing supplements and patients were shown a list of commonly available multivitamins containing Vitamin B12 and were asked about their use at any time in the past.

Data analysis: Data were all entered into MS excel and subjected to appropriate statistical tests like descriptive and inferential statistical analysis. Results on continuous measurements are presented as Mean \pm SD and results on categorical measurements are presented in Number (\%). In this study, levels of vitamin B12 are interpreted as

$<200 \mathrm{pg} / \mathrm{m} / \mathrm{ml}$-low vitamin B12 levels

$>300$ pg/ml-normal vitamin B12 levels

Ethical consideration: The purpose of study was explained to all patients and informed consent taken from them. Ethical committee clearance was taken

\section{Results}

Women in the age group 30-70 years were included in the study. Most women were in the age group 5155 years which included 195 patients (30\%)

Table-1: Age distribution of patients studied

\begin{tabular}{|l|l|l|}
\hline \multicolumn{1}{|c|}{ Age in years } & \multicolumn{1}{|c|}{ No. of patients } & \multicolumn{1}{c|}{$\%$} \\
\hline$<40$ & 33 & 5 \\
\hline $41-50$ & 162 & 25 \\
\hline $51-55$ & 195 & 30 \\
\hline $56-60$ & 156 & 24 \\
\hline $61-65$ & 65 & 10 \\
\hline $66-70$ & 39 & 6 \\
\hline Total & 650 & 100.0 \\
\hline
\end{tabular}

The youngest patient was aged 32 years while the oldest patient was aged 68 years. Mean age of the study group was $51.98 \pm 5.17$ years, while it was $49.28 \pm 5.08$ in control group, which was statistically non-significant.

Table-2: Duration of DM

\begin{tabular}{|l|l|}
\hline \multicolumn{1}{|c|}{ Duration (years) } & \multicolumn{1}{c|}{ No of patients (\%) } \\
\hline$<5$ & $80(12.3)$ \\
\hline $5-10$ & $210(32.3)$ \\
\hline $10-15$ & $250(38.4)$ \\
\hline$>15$ & $110(16.9)$ \\
\hline
\end{tabular}

The duration of diabetes in case ranged from 1.5 to 
20 years with the mean of $9.15 \pm 4.33$ years while in controls it ranged from 1.8 to 16 years with a mean of $7.44 \pm 3.82$ years.

Table-3: Comparison of serum Vitamin B12 levels in cases and controls

\begin{tabular}{|l|l|l|}
\hline & \multicolumn{1}{|c|}{$\begin{array}{c}\text { Low Vitamin B12 levels } \\
(\%)\end{array}$} & \multicolumn{1}{|c|}{$\begin{array}{c}\text { Normal Vitamin B12 levels } \\
(\%)\end{array}$} \\
\hline Cases (408) & $164(40.1)$ & $244(59.8)$ \\
\hline $\begin{array}{l}\text { Controls } \\
(242)\end{array}$ & $22((9)$ & $220(90.9)$ \\
\hline
\end{tabular}

Cases are defined as those diabetic patients on Metformin therapy for more than 3 months. Controls are those diabetics who have never been on Metformin. Normal Vitamin B12 levels are

Table-4: Comparison of duration of diabetes with Vitamin B12 levels in cases

\begin{tabular}{|l|l|l|}
\hline Duration of DM & Low Vitamin B12 (\%) & Normal Vitamin B12 (\%) \\
\hline$<1$ year & $14(8.5)$ & $87(35.7)$ \\
\hline $1-5$ years & $18(11.1)$ & $86(35.1)$ \\
\hline $6-10$ years & $41(25)$ & $36(14.8)$ \\
\hline $11-20$ years & $41(25)$ & $14(5.9)$ \\
\hline$>20$ years & $50(30.5)$ & $21(8.3)$ \\
\hline Total & 164 & 244 \\
\hline
\end{tabular}

Mean Serum vitamin B12 in study group among patients with duration of DM of less than 5 years was $505.47 \pm 275.24 \mathrm{pg} / \mathrm{ml}$, while mean S. vitamin B12 in patients with duration of diabetes more than 5 years was $321.40 \pm 212.43 \mathrm{pg} / \mathrm{ml}$. The difference between the two is statistically significant ( $p=$ 0.015).

Table-5: Comparison of daily dosage of metformin with vitamin B12 levels in case

\begin{tabular}{|l|l|l|}
\hline \multicolumn{1}{|c|}{$\begin{array}{c}\text { Daily dosage of } \\
\text { metformin }\end{array}$} & \multicolumn{1}{|c|}{$(\%)$} & \multicolumn{1}{|c|}{$(\%)$} \\
\hline$<1 \mathrm{~g}$ & $50(30.5)$ & $90(36.9)$ \\
\hline $1-2 \mathrm{~g}$ & $36(22.2)$ & $118(48.5)$ \\
\hline$>2 \mathrm{~g}$ & $78(47.2)$ & $35(14.5)$ \\
\hline Total & 164 & 244 \\
\hline
\end{tabular}

Patients taking a higher dose of metformin had low levels of Vitamin B12 compared to lower dose of metformin.

Table-6: Association of serum Vitamin B12 levels with complications in cases

\begin{tabular}{|c|c|c|}
\hline & $\begin{array}{l}\text { Low Vitamin B12 } \\
\qquad(\mathrm{n}=164)(\%)\end{array}$ & $\begin{array}{l}\text { Normal Vitamin B12 } \\
\qquad(n=244)(\%)\end{array}$ \\
\hline $\begin{array}{l}\text { Low } \\
\text { hemoglobin }\end{array}$ & $74(45.1)$ & $66(27)$ \\
\hline Raised MCV & 88 (53.6) & $26(10.6)$ \\
\hline
\end{tabular}

\begin{tabular}{|l|l|l|}
\hline Symptoms of PN & $149(90.8)$ & $128(52.4)$ \\
\hline NCS proven PN & $132(80.4)$ & $112(45.9)$ \\
\hline Dementia & $4(2)$ & $6(2.4)$ \\
\hline
\end{tabular}

Cases with low levels of Vitamin B12 developed complications like peripheral neuropathy (90\%), anemia (45\%), macrocytosis (53.6\%). Dementia was the least common complication observed in $2 \%$ of cases, peripheral neuropathy being the commonest $(90 \%)$.

Table-7: Association of Vitamin B12 levels with associated co morbiditiesin cases

\begin{tabular}{|l|l|l|}
\hline \multicolumn{1}{|c|}{ Co-morbid conditions } & \multicolumn{1}{|c|}{$\begin{array}{c}\text { Low Vitamin B12 } \\
(\%)\end{array}$} & \multicolumn{1}{|c|}{$\begin{array}{c}\text { Normal Vitamin B12 } \\
(\%)\end{array}$} \\
\hline Hypertension (213) & $72(33.8)$ & $141(66.1)$ \\
\hline Smoking (03) & $01(33.3)$ & $02(66.6)$ \\
\hline $\begin{array}{l}\text { Coronary artery disease } \\
(72)\end{array}$ & $24(33.3)$ & $48(66.6)$ \\
\hline Obesity (202) & $125(61.8)$ & $77(38.1)$ \\
\hline Insulin treatment (64) & $32(50)$ & $32(50)$ \\
\hline Dyslipidaemia (128) & $68(53.1)$ & $60(46.8)$ \\
\hline
\end{tabular}

Hypertension and obesity were the most common comorbities associated with DM. 33\% of cases with Hypertension and $61 \%$ with obesity had low Vitamin B12 levels. DM with obesity poses a greater risk for Vitamin B12 deficiency.

Table-8: Demographic details of cases and controls.

\begin{tabular}{|l|l|l|l|}
\hline & Cases (408) & \multicolumn{1}{|c|}{ Controls (242) } & P value \\
\hline Age, Mean (SE) & $56.2(0.8)$ & $58.3(0.75)$ & $<0.0001$ \\
\hline Years of DM, Mean (SE) & $11.2(0.7)$ & $12.3(0.6)$ & 0.02 \\
\hline Insulin use $\mathrm{n}(\%)$ & $84(20.5)$ & $122(50.4)$ & 0.013 \\
\hline Take calcium $\mathrm{n}(\%)$ & $210(51.47)$ & $140(57.8)$ & 0.89 \\
\hline Normal BMI $(\mathrm{kg} / \mathrm{m} 2)$ & $150(36.7)$ & $62(25.6)$ & 0.098 \\
\hline BMI 25-30 $\mathrm{n}(\%)$ & $212(51.9)$ & $140(57.8)$ & \\
\hline Obese $\mathrm{n}(\%)$ & $46(11.2)$ & $40(16.5)$ & \\
\hline
\end{tabular}

In the study group BMI ranged from 17 to $38 \mathrm{~kg} / \mathrm{m} 2$ with a mean of $30.2 \pm 3.73 \mathrm{~kg} / \mathrm{m} 2$. In the control group BMI ranged from 19 to $32 \mathrm{~kg} / \mathrm{m} 2$ with a mean of $27.61 \pm 2.98 \mathrm{~kg} / \mathrm{m} 2$. Significantly higher mean was observed in mean BMI in cases as compared to controls.

\section{Discussion}

A total of 650 diabetic women were studied. The mean age of the cases was $51.98 \pm 5.17$ years. The age group studied was similar to that observed by Agarwal $P$ et al study [1] and Raizada $N$ et al [10]. The duration of diabetes in cases ranged from 1.5 to 20 years with the mean of $9.15 \pm 4.33$ years while in 
Controls it ranged from 1.8 to 16 years with a mean of $7.44 \pm 3.82$ years. This was comparable to Agarwal et al study where mean duration of Dm was $6.15 \pm 3.33$ years in cases and $3.44 \pm 1.82$ years in controls [1].

In the present study, $164(40.1 \%)$ patients in cases group had low Vitamin B12 levels as against 22 $(9 \%)$ in control group. In different studies, Vitamin B12 deficiency was found in 5.8\%, 8.6\%, 6.3\%, of patients with type 2 diabetes mellitus on metformin $[11,12,13]$. In the cases, $\mathrm{S}$. vitamin $\mathrm{B} 12$ ranged from 155 to $580 \mathrm{pg} / \mathrm{ml}$ with a mean of $242 \pm 42.6$. In the controls, serum vitamin B12 ranged from 162 to $742 \mathrm{pg} / \mathrm{ml}$ with a mean of $312 \pm 90.27$.

Significantly lower mean serum vitamin B12 was observed in cases as compared to controls $(p=0.002)$, similar to results from other studies [9, 11]. In one early randomized control trial by DeFronzo et al, metformin decreased the serum vitamin B12 levels by $22 \%$ and $29 \%$ compared to placebo and glyburide respectively [2]. Metformin use has been unequivocally demonstrated as the prime factor associated with vitamin B12 deficiency among patients with T2DM [3, 11, 14-18].

Levels of Vitamin B12 decreased with an increase in duration of DM and also with increase in daily dosage of metformin. The impact of Vitamin B12 deficiency on hemato-logical parameters such as MCV and hemoglobin as well as on peripheral neuropathy was studied.

A decrease in hemoglobin and increase in MCV in the Vitamin B12-deficient patients was observed in the present study. The nerve conduction studies were positive in a greater percentage of patients who had low Vitamin B12 levels. In other studies, Vitamin B12 deficiency did not impact hematological or neurological parameters assessed [17].

Significantly higher mean was observed according to mean BMI in cases as compared to controls $(p=0.016)$. Similar results were observed by studies done in the past.

A large proportion of Asian and Chinese patients with type 2 diabetes are of normal weight: a recently published pooled cross-sectional analysis of 39,794 diabetes patients from Asia (most of whom had type 2 diabetes), revealed that $64 \%$ had a BMI $<25 \mathrm{~kg} / \mathrm{m} 2$ [2].

\section{Conclusion}

Metformin treatment in diabetic women is associated with higher prevalence of Vitamin B12 deficiency. Deficiency of Vitamin B12 increases with duration of DM and dose of metformin. Vitamin B12 deficiency did have an impact on development of macrocytic anemia and worsening of neuropathy.

Some symptoms of vitamin B12 deficiency are difficult to diagnose and can be irreversible if left untreated (like neuropathy). On the other hand, treatment of vitamin B12 deficiency is relatively easy, cheap, safe, and effective.

This study had certain limitations like a smaller sample size was included. Functional markers of Vitamin B12 deficiency were not estimated (serum homocysteine and serum methylmalonic acid levels) which may better reflect the status of Vitamin B12 levels in the body as compared to serum Vitamin B12 levels.

Routine screening of Serum Vitamin B12 levels, complete hemogram, and neuropathy status should be done in all diabetic women at the beginning of metformin therapy, and every 1-2 years thereafter.

If any diabetic woman is found to be having low levels of Vitamin B12, they should be well supplemented with the Vitamin before start of metformin therapy in them. Another approach is to compulsorily administer $1000 \mu \mathrm{g}$ of Vitamin B12 injection once a year in all diabetic patients on metformin therapy.

\section{What the study adds to the existing knowledge?}

This study compared the prevalence of vitamin B12 deficiency in metformin users and non-users, and subdivided metformin use on the basis of two factors: length of use and dosage per day.

The majority of cases of vitamin B12 deficiency were in metformin users, which indicates that metformin might influence serum vitamin B12 levels. Current guidelines do not recommend routinely checking B12 levels in all diabetic patients.

Therefore, it is recommend routine screening for serum vitamin B12 in individuals with T2DM who take daily metformin doses higher than $2,000 \mathrm{mg}$, or for a duration exceeding 4 years. 
Patients taking metformin should have their vitamin B12 levels assessed regularly to avoid peripheral nerve damage.

\section{Author recommendations}

Routine screening of Serum Vitamin B12 levels, complete hemogram, and neuropathy status should be done in all diabetic women at the beginning of metformin therapy, and every 1-2 years thereafter. If any diabetic woman is found to be having low levels of Vitamin B12, they should be well supplemented with the Vitamin before start of metformin therapy. Another approach is to compulsorily administer $1000 \mu \mathrm{g}$ of Vitamin B12 injection once a year in all diabetic patients on metformin therapy.

\section{Reference}

01. Agarwal P, Mital P, Meena VK, Mital P, Nawal CL, Goyal KL. A comparative study of levels of vitamin $\mathrm{B} 12$ in patients of type 2 diabetes mellitus on metformin and not on metformin at tertiary care center. Int J Adv Med. 2016;3(3)759-763.

doi: 10.18203/2349-3933.ijam20162531 [Crossref]

02. Defronzo RA, Goodman AM. Efficacy of metformin in patients with non-insulindependent diabetes mellitus- The Multicenter Metformin Study Group. N Engl J Med. 1995;333(9)541-9.

doi:10.1056/NEJM199508313330902 [Crossref]

03. Kos E, Liszek M, Emanuele M, Durazo-Arvizu R, Camacho $P$. Effect of metformin therapy on vitamin $D$ and vitamin $B_{12}$ levels in patients with type 2 diabetes mellitus. Endocr Pract. $2012 ; 18(2) 179-184$.

doi: $10.4158 / E P 11009.0 R \quad$ [Crossref]

04. Yajnik C, Deshpande SS, Lubree HG, Naik SS, Bhat DS, Uradey BS, et al. Vitamin B12 deficiency and hyperhomocysteinemia in rural and urban Indians. J Assoc Physicians India. $2006 ; 54 ; 775-782$.

[Crossref]

05. Kapil U, Bhadoria AS. Prevalence of folate, ferritin and cobalamin deficiencies amongst adolescent in India. J Family Med Prim Care. 2014;3(3)247-249.

doi: $10.4103 / 2249-4863.141619$ [Crossref]
06. Ting RZ, Szeto CC, Chan MH, Ma KK, Chow KM. Risk factors of vitamin $B(12)$ deficiency in patients receiving metformin. Arch Intern Med. 2006;166(18)1975-1979.

doi: 10.1001/archinte.166.18.1975 [Crossref]

07. Bauman WA, Shaw S, Jayatilleke E, Spungen AM, Herbert V. Increased intake of calcium reverses vitamin $\mathrm{B} 12$ malabsorption induced by metformin. Diabetes Care. 2000;23(9) 1227-31. doi: $10.2337 /$ diacare.23.9.1227 [Crossref]

08. Harinarayan CV, Ramalakshmi T, Prasad UV, Su dhakar D, Srinivasarao PV, Sarma KV, et al. High prevalence of low dietary calcium, high phytate consumption, and vitamin $\mathrm{D}$ deficiency in health y south Indians. Am J Clin Nutr. 2007;85(4)

1062-7. doi: 10.1093/ajcn/85.4.1062 [Crossref]

09. Mazokopakis EE, Starakis IK. Recommendations for diagnosis and management of metformininduced vitamin B12 (Cbl) deficiency. Diabetes Res Clin Pract. 2012;97(3)359-367.

doi: 10.1016/j.diabres.2012.06.001 [Crossref]

10. Raizada N, Jyotsna VP, Sreenivas V, Tandon N. Serum Vitamin B12 Levels in Type 2 Diabetes Patients on Metformin Compared to those Never on Metformin- A Cross-sectional Study. Indian J Endocrinol Metab. 2017;21(3)424-428. doi: 10.4103/ijem.IJEM_529_16 [Crossref]

11. Reinstatler L, Qi YP, Williamson RS, Garn JV, Oakley GP. Association of biochemical $\mathrm{B}_{12}$ deficiency with metformin therapy and vitamin B12 supplements- the National Health and Nutrition Examination Survey, 1999-2006. Diabetes Care. 2012;35(2)327-333. doi: $10.2337 / \mathrm{dc} 11-1582$ [Crossref]

12. Calvo Romero JM, Ramiro Lozano JM. Vitamin B (12) in type 2 diabetic patients treated with metformin. Endocrinol Nutr. 2012;59(8)487-90.

doi: $10.1016 /$ j.endonu.2012.06.005 [Crossref]

13. Nervo $M$, Lubini $A$, Raimundo FV, Faulhaber GA, Leite $C$, Fischer LM et al. Vitamin B12 in metfor min-treated diabetic patients a cross-sectional $\mathrm{s}$ tudy in Brazil. Rev Assoc Med Bras. 2011;57(1) 46-9. doi: 10.1590/S0104-42302011000100015 [Crossref] 
14. De Jager J, Kooy A, Lehert $P$, Wulffelé MG, Van der Kolk J, Bets D, et al. Long-term treatment with metformin in patients with type 2 diabetes and risk of vitamin B-12 deficiency- randomised placebo-controlled trial. BMJ. 2010;340;c2181. doi: $10.1136 / \mathrm{bmj} . c 2181$ [Crossref]

15. Ting RZ, Szeto CC, Chan MH, Ma KK, Chow KM. Risk factors of vitamin $B(12)$ deficiency in patients receiving metformin. Arch Intern Med. 2006;166(18)1975-1979.

doi: 10.1001/archinte.166.18.1975 [Crossref]

16. Green SM, Watson R. Nutritional screening and assessment tools for older adults- literature review. J Adv Nurs. 2006;54(4)477-90.

doi: $10.1111 /$ j.1365-2648.2006.03841.x [Crossref]
17. Groenier $\mathrm{KH}$, Houweling ST, Bilo $\mathrm{HJ}$, Kleefstra N. Vitamin B12 deficiency and the lack of its consequences in type 2 diabetes patients using metformin. Neth J Med. 2013;71(7)386-390.

[Crossref]

18. Anil Kumar R, Surekha B Shetty, Lalitha R. Prevalence of vitamin B12 deficiency in Indian type 2 diabetes subjects on metformin therapy. Int J Med Res Rev. 2017;5(09)845-850. doi: 10.17511/ijmrr.2017.i09.03 [Crossref] 